\title{
Preparation, Properties and Applications of the Hybrid Organic/Inorganic Nanocomposite Based on Nanoporous Carbon Matrix
}

NABIL BEN MANSOUR ( $\sim$ Benmansour.nabil@yahoo.fr)

Gabes University https://orcid.org/0000-0002-7936-8304

Wahid Djeridi

Gabes University

Lassaad El Mir

Gabes University

\section{Research Article}

Keywords: Sol-gel, Nanoporous carbon matrix, hybrid nanocomposite, Gas storage, Negatronic devices, Non-enzymatic glucose sensor.

Posted Date: April 27th, 2021

DOl: https://doi.org/10.21203/rs.3.rs-431372/v1

License: (c) (i) This work is licensed under a Creative Commons Attribution 4.0 International License. Read Full License 


\section{Preparation, properties and applications of the hybrid organic/inorganic nanocomposite based on nanoporous carbon matrix}

N. Ben Mansoura, ${ }^{a,}$, W. Djeridi ${ }^{\mathrm{b}}$ and L. El Mir ${ }^{\mathrm{a}}$

${ }^{a}$ Laboratory of physics of Materials and Nanomaterials Applied At Environment (LaPhyMNE), Faculty of Sciences in Gabes, Gabes University, 6072 Gabes, Tunisia.

${ }^{b}$ Research Laboratory: Engineering Process and Industrial Systems, Gabes University, National school of Engineers of Gabes, Gabes, Tunisia.

*Corresponding author, Tel:0021697901939

E-mail adress: Nabil.Benmansour@fsg.rnu.tn, Benmansour.nabil@yahoo.fr

(N. BEN MANSOUR) 


\section{Abstract}

Nanoporous carbon matrix was prepared by the sol-gel process from pyrogallol-formaldehyde (PF) mixtures in water using picric acid as catalyst. For the second sample, nickel oxide nanoparticles were added in the PF matrix to get a PF/NiO hybrid nanocomposite. The samples were heat treated at the pyrolysis temperature of $650{ }^{\circ} \mathrm{C}$ for two hours. The obtained materials have been characterized by different techniques such as: X-ray diffraction (XRD), scanning electron microscope (SEM), transmission electron microscopy (TEM), thermogravimetric analysis (TGA), differential thermalanalysis (DTA),nitrogen adsorption-desorption isotherms, voltage-current characteristics, electrochemical measurementsand UV-Vis-IR absorption. The XRD analysis shows that PF matrix is amorphous while $\mathrm{PF} / \mathrm{NiO}$ nanocomposite exhibited a metallic phase of nickel. The SEM and TEM images indicated the presence of nickel particles in the $\mathrm{PF} / \mathrm{NiO}$ nanocomposite which are dispersed randomly in the carbon matrix. The adsorption-desorption of nitrogen revealed that the $\mathrm{PF}$ matrix is microporous and the $\mathrm{PF} / \mathrm{NiO}$ nanocomposite is mesoporous. The adsorption capacities of carbon dioxide $\left(\mathrm{CO}_{2}\right)$ and methane $\left(\mathrm{CH}_{4}\right)$ show that the PF matrix has the highest adsorption at low pressures and the $\mathrm{PF} / \mathrm{NiO}$ nanocomposite tends to adsorb gases better at high pressure. The $\mathrm{V}(\mathrm{I})$ characteristics showed that the $\mathrm{PF} / \mathrm{NiO}$ nanocomposite can be considered as a smart material. Indeed, the characteristic behavior can be adjusted according to the maximum applied current. Electrochemical measurements have shown that the $\mathrm{PF} / \mathrm{NiO}$ nanocomposite is very promising for the detection of non-enzymatic glucose. The absorption spectra showed that the addition of the $\mathrm{NiO}$ nanoparticles increased the disorder. The obtained materials are promoters for various applications such as gas storage, negatronic devices and glucose sensor.

Keywords: Sol-gel; Nanoporous carbon matrix; hybrid nanocomposite; Gas storage; Negatronic devices; Non-enzymatic glucose sensor. 


\section{Introduction}

The nanoporous carbon matrix has been widely used to elaborate promising materials in several areas like the adsorption and separation of greenhouse gases [1,2]. Indeed, this matrix presents a unique pore structure, high stability and low preparation cost $[3,4]$. The nanoporous carbon matrix based on pyrogallol-formaldehyde (PF) is one of the organic gels known by itspromising characteristics depending on the synthesis conditions [5]. In fact, pyrogallol is considered among the materials which are very good absorbers of water. For this reason, water was chosen as solvent to extract it with conventional drying and thus obtaining a very porous material to use it in the field of gas storage. Thanks to these specific morphological and textural properties, this nanoporous matrix can have significant greenhouse gas adsorption like carbon dioxide and methane. Generally, $\mathrm{CO}_{2}$ and $\mathrm{CH}_{4}$ emissions are very responsible for current global warming and also for health problems. For that, the development of different materials, methods and process are essential for the sequestration of these gases. There are several technologies for capture but adsorption are considered to be among the most effective separation processes [6,7]. Currently, research focuses on the elaboration of different families of porous materials that can capture these two gases [8,9]. Among the materials which have been applied as adsorbents, we can cite: mesoporous silica [10,11], organometallic reinforcementmaterials [12,13] and microporous organic polymers $[14,15]$.

The incorporation of metal oxide nanoparticles in the nanoporous carbon matrix fallows as to obtain of the different types of hybrid organic/inorganic nanocomposites [16-18]. In recent years, these hybrid nanocomposites have received a great deal of attention from researchers from an applied or fundamental perspectives $[19,20]$. They are widely used in various applications such as; photovoltaic cells [21], hydrogen storage [22], negatronic devices [23] and electrochemical devices such as sensors [24]. In fact, the metal oxide 
nanoparticles are scientifically and technologically interesting functional materials with a variety of properties spanning nearly all aspects of materials science and physics. They are very important for research because of their importance in applications in biology, environment, analytical chemistry and physics [25]. Indeed, these nanoparticles have a high surface/volume ratio, low toxicity, high chemical stability and they have exhibit fast electron transfer properties to improve the performance of nanomaterials when used as biomimetic membranes for example to detect proteins and retain their activity [26,27]. Nevertheless, the incorporation of metal oxide nanoparticles into the nanoporous carbon matrix has paved the way for a new generation of materials with unique electrical and optical properties that make them attractive for applications in different fields such as optoelectronics [28], sensor design [29,30], catalysis [31] and antimicrobial coatings [32]. So, the synthesis of porous organic/inorganic nanocomposites has opened up new possibilities for manufacturing electrochemical sensors such as non-enzymatic glucose sensors. The non-enzymatic glucose sensors is a focused research area with increasing attention in order to well-known rising demands for advanced blood sugar detection devices for clinical diagnosis, ecological and pharmaceutical analysis $[33,34]$. The principle of non-enzymatic glucose sensor is based on the direct electrocatalytic oxidation of glucose; the key factor being the electrocatalytic activity of the electrode material, which affects both sensitivity and selectivity $[35,36]$. In particular, nickel nanoparticles have been widely used for glucose sensing due to relatively low cost, high electrocatalytic activity and good selectivity for the glucose oxidation. Most nickel based non enzymatic glucose sensors are also prepared by modifying suitable substrates with nickel nanoparticles $[37,38]$ or carbon/nickel nanocomposites $[39,40]$.

The principal objectives of this work is the synthesis, characterization and the illustration of some potential applications of a $\mathrm{PF}$ nanoporous carbon matrix and $\mathrm{PF} / \mathrm{NiO}$ hybrid nanocomposite obtained by the incorporating of $\mathrm{NiO}$ nanoparticles in the PF matrix. 
Particular interest was given to the effect of the addition of nickel oxide nanoparticles on the adsorption of $\mathrm{CO}_{2}$ and $\mathrm{CH}_{4}$ at room temperature, the $\mathrm{V}(\mathrm{I})$ characteristic as a function of the maximum applied current and finally on the electrochemical glucose oxidation.

\section{Experimental procedure}

\section{II.1. Preparation}

The preparation of the PF nanoporous carbon matrix and the $\mathrm{PF} / \mathrm{NiO}$ hybrid nanocomposite were carried out by sol-gel method. For the synthesis of PF matrix, first of all we have dissolved the pyrogallol $(\mathrm{P})$ and the formaldehyde $(\mathrm{F})$ in water $(\mathrm{W})$, then the reaction has been activated by picric acid. In a second stage, the wet gel was dried in humid atmosphere at $50{ }^{\circ} \mathrm{C}$ for 15 days. In order to avoid any shrinkage of the obtained xerogel monolith, the wet gel was transferred to an incubator and dried at $150{ }^{\circ} \mathrm{C}$ at a heating rate of $10{ }^{\circ} \mathrm{C} /$ day. To obtain $\mathrm{PF} / \mathrm{NiO}$ nanocomposite, $\mathrm{NiO}$ nanoparticles were first prepared from the precursor of nickel (II) chloride $\left(\mathrm{NiCl}_{2}, 6 \mathrm{H}_{2} \mathrm{O}\right)$ using sol-gel process as per El Mir et al. protocol [41]. In this process the precursor was dissolved in methanol; after 15 min under magnetic stirring at room temperature, the solution was then placed in an autoclave and dried in supercritical conditions of ethyl alcohol. Secondly, the prepared aerogel were annealed at $500{ }^{\circ} \mathrm{C}$ in air for two hours. Thereafter, the synthesized nanoparticles were incorporated in PF nanoporous matrix with mass proportion of 5\%. Finally, the $\mathrm{PF} / \mathrm{NiO}$ nanocomposite was obtained after a conventional drying like that of the PF matrix. In the present investigation, the annealing of our samples ( $\mathrm{PF}$ matrix and $\mathrm{PF} / \mathrm{NiO}$ nanocomposite) was done in a tubular furnace under controlled atmosphere of nitrogen at $650{ }^{\circ} \mathrm{C}$ during two hours with a heating rate of $5{ }^{\circ} \mathrm{C} / \mathrm{min}$. After that, the samples were cooled naturally. For electrical measurements, the samples were prepared by sculpting monoliths on a parallelepipedic shape $(12 \times 6 \times 3) \mathrm{mm}^{3}$ and silver paint on two parallel faces was performed to assure the ohmic contact. For electrochemical measurements, the preparation of the modified sensors, $5 \mathrm{mg}$ of each PF and 
$\mathrm{PF} / \mathrm{NiO}$ powder were dispersed in double distilled water than sonicated until homogenous black suspensions were obtained. A cell of three-electrode was used which comprises: a commercial screen printed carbon based working electrode of diameter equal to $4 \mathrm{~mm}$, a carbon counter electrode which ensures the passage of current through the electrolyte and a silver reference electrode which makes it possible to impose an electric potential on the working electrode which has been modified by wet impregnation; by pouring $5 \mu$ of the suspension prepared on its surface and then allowing it to dry at room temperature.

\section{II.2. Characterization}

The crystalline phases of the obtained samples were identified by X-ray diffraction (XRD) from a Bruker D5005 powder X-ray diffractometer using a CoK $\alpha$ radiation. The synthesized samples were characterized using a JEOL JSM-5310 scanning electron microscope (SEM) and a JEOL-100C transmission electron microscope (TEM). For thermal gravimetric analysis (TGA) and differential thermal analysis (DTA), a Seteram LabsysTM system was used to determine the effect of annealing on the weight loss and on the corresponding thermal of our xerogels samples during pyrolysis in nitrogen atmosphere at an annealing rate of $5{ }^{\circ} \mathrm{C} / \mathrm{min}$ to $800{ }^{\circ} \mathrm{C}$. The specific surface area, the micropore volume and the micropore width were determined by $\mathrm{N}_{2}$ adsorption-desorption isotherms at $77 \mathrm{~K}$ using the micrometrics ASAP2000 equipment. The adsorption measurements of $\mathrm{CH}_{4}$ and $\mathrm{CO}_{2}$ were measured at low and high pressure in a homemade automatic volumetric apparatus. Before starting the measurement isotherms, we used an $80 \mathrm{mg}$ mass of each sample which was thermally activated individually under primary vacuum at $150{ }^{\circ} \mathrm{C}$ overnight. The used gases arevery clean: methane was of $99.9995 \%$ purity and carbon dioxide was of $99.995 \%$ purity. Voltage-current measurements were performed using a computer-controlled setup comprising an Agilent 34401A multimeter and a Keithley 220 current source in a temperature range from 80 to $300 \mathrm{~K}$ under vacuum using a liquid nitrogen cryostat. Impedance measurements were 
performed by an Agilent 4294A impedance analyzer. The electrochemical behavior was investigated by cyclic voltammetry in $0.1 \mathrm{M} \mathrm{KOH}$ solution for a potential range $0-1 \mathrm{~V}$, in presence and absence of glucose and at a scan rate equal to $50 \mathrm{mVs}^{-1}$ with a DropSens $\mu$ Stat 400 potentiostat/galvanostat. The optical absorbance of the materials was determined using Schimadzu UV-3101 PC spectrophotometer with integrating sphere in the wavelength range from 200 to $2400 \mathrm{~nm}$.

\section{Results and discussions}

The XRD patterns of the obtained PF matrix and PF/NiO nanocomposite are reported in Fig. 1.Two broad diffraction peaks at about $24^{\circ}$ and $42^{\circ}$ attributed to (002) and (100) planes typical of amorphous carbon were observed in the PF matrix. On the other hand, the $\mathrm{PF} / \mathrm{NiO}$ nanocomposite is crystallized. Indeed, there is the appearance of three distinct reflection peaks at $44^{\circ}, 51^{\circ}$ and $76^{\circ}$ which match with the (111), (200), (220) planes of metallic nickel. The crystallite size of $\mathrm{PF}$ matrix and $\mathrm{PF} / \mathrm{NiO}$ nanocomposite were estimated from the Scherrer's formula Eq. (1) [42]:

$$
G=\frac{0.9 \lambda}{B \cos \theta_{B}}
$$

where $\lambda$ is the X-ray wavelength, $\theta_{\mathrm{B}}$ is the maximum of the Bragg diffraction peak and $\mathrm{B}$ is the line width at half maximum. The dimension of the crystallites deduced using Eq. (1), indicates that the average value of graphite crystallites increases from $2 \mathrm{~nm}$ in the PF matrix to $3.5 \mathrm{~nm}$ in the $\mathrm{PF} / \mathrm{NiO}$ nanocomposite and for the metallic nickel is of the order of $35 \mathrm{~nm}$. From these results, it can be deduced that the incorporation of $\mathrm{NiO}$ nanoparticles into the carbon matrix under the impact of pyrolysis temperature equal to $650{ }^{\circ} \mathrm{C}$ leads to the change of crystalline properties of $\mathrm{PF} / \mathrm{NiO}$ nanocomposite compared to those of $\mathrm{PF}$ matrix. 
The SEM observations for the considered samples are outlined in Fig. 2. As indicated by these images, the two materials are made by agglomerated of carbon microspheres. The $\mathrm{PF} / \mathrm{NiO}$ nanocomposite shows a more compact carbon matrix, thanks to the presence of metallic nickel microparticles which can increase the active surface of this nanocomposite.

TEM image in Fig. 3a depicts that this is an agglomeration of the nanoparticles in PF matrix with the presence of a space between the nanoparticles which confirms the existence of nanopores. Fig. $3 \mathrm{~b}$ shows that the $\mathrm{PF} / \mathrm{NiO}$ nanocomposite consists of metallic nickel nanoparticles which are dispersed in an amorphous carbon matrix. The metallic nickel nanoparticles average size is around $30 \mathrm{~nm}$. These images are consistent with the results obtained by XRD.

The results from thermal gravimetric analysis indicate a total weight loss of about $67 \%$ for PF matrix (Fig. 4a) and 60\% for PF/NiO nanocomposite (Fig. 4b) during pyrolysis in $\mathrm{N}_{2}$. This difference between the values of weight loss between the two samples can be explained by the presence of metallic nickel in the $\mathrm{PF} / \mathrm{NiO}$ nanocomposite which was not lost during thermal treatment. A first endothermic peak was observed at $110{ }^{\circ} \mathrm{C}$ for the two materials, which corresponds to the desorption of water. The second appeared only in the PF/NiO nanocomposite at $150{ }^{\circ} \mathrm{C}$ is due to the crystallisation of this nanocomposite activated by the NiO phase. Then, for a temperature close to $700{ }^{\circ} \mathrm{C}$, there is the presence of a third peak which can be explained by the formation of multiwalled carbon nanotubes $[43,44]$. On the other hand, an exothermic peak has been observed around $230{ }^{\circ} \mathrm{C}$ only in the PF matrix thanks to the desorption of the organic residues of the precursors and of the catalyst.

The adsorption-desorption isotherms of the samples are illustrated in Fig. 5. According to the Brunauer Emett and Teller (BET) classification, the isotherm of PF matrix shows that is of type I and for that of PF/NiO nanocomposite is of type IV. The different porosity parameters and the electrical conductivity values of our materials are assembled in 
Table 1. It can be deduced from this study, that the PF matrix is microporous and the $\mathrm{PF} / \mathrm{NiO}$ nanocomposite is mesoporous. Indeed, the pore size is of about $1.9 \mathrm{~nm}$ for the PF matrix and $2.6 \mathrm{~nm}$ for the $\mathrm{PF} / \mathrm{NiO}$ nanocomposite. The specific surface area and the pore volume have been reduced in the $\mathrm{PF} / \mathrm{NiO}$ nanocomposite compared to that of $\mathrm{PF}$ matrix which can be attributed to the effect of the Ni nanoparticles. In fact, the Ni nanoparticles probably filled the pores in the PF matrix and subsequently increased the electrical conductivity of the PF/NiO nanocomposite.

The adsorption capacity of $\mathrm{CO}_{2}$ and $\mathrm{CH}_{4}$ of our materials is presented in Fig. 6. It is clear that the adsorption capacity of $\mathrm{CO}_{2}$ is higher than that of $\mathrm{CH}_{4}$. Indeed, the $\mathrm{CO}_{2}$ molecule has a linear shape which can perform specific interactions with the adsorbent unlike the $\mathrm{CH}_{4}$ molecule which is tetrahedral. Also, the experimental temperature used during the adsorption equal to $302 \mathrm{~K}$, very close to the temperature of the critical point of $\mathrm{CO}_{2}$. Thus, the adsorption of $\mathrm{CO}_{2}$ under these experimental conditions will be favored than the $\mathrm{CH}_{4}$. We have shown in ourprevious works that the main factors acting on the adsorption properties of $\mathrm{CO}_{2}$ and $\mathrm{CH}_{4}$ are the specific surface area and the volume of the pores $[45,46]$. But we note that for this study as shown in the table 2, at low pressures (5 bar), the PF matrix has the highest adsorption capacity for the two gases and at high pressures ( 25 bar), the PF/NiO nanocomposite tends to adsorb gases better than the PF matrix. In fact, for low pressures the adsorption takes place in the micropores which are dominant in the PF matrix and for high pressures the adsorbed molecules fill the mesopores which exist in the $\mathrm{PF} / \mathrm{NiO}$ nanocomposite. These results are in good agreement with those obtained by Almasi et al. for the study of three-dimensional microporous coordination polymers [47].

Fig. 7 shows the voltage-current characteristics of our materials at $120 \mathrm{~K}$ measurement temperature. For PF matrix (Fig. 7a), the variation is reversible and the maximum current applied has no effect on the change of the V(I) characteristic. However, the 
characteristic is irreversible in $\mathrm{PF} / \mathrm{NiO}$ nanocomposite (Fig. 7b) with the presence of a negative differential resistance in the two paths (ascending and descending current). It can be deduced from this study, that the maximum current applied to this nanocomposite has changed its behavior and it has become more conductive. This dependence of the maximum current applied to the $\mathrm{PF} / \mathrm{NiO}$ nanocomposite can be explained by the high thermal conductivity of metallic nickel which produced metallic filaments inside the material and which gave a temperature discontinuity at the atmosphere-sample interface. This material takes the final characteristic of the second path (descending current) provided that the maximum current does not exceed $9 \mathrm{~mA}$. This $\mathrm{PF} / \mathrm{NiO}$ nanocomposite can be considered among the smart materials because their electrical properties can be adjusted by the maximum current applied. In literary, smart materials are able to sense environmental changes and activate their properties according to these changes. Nowadays, the most developed intelligent materials are network polymers, electrorheological fluids, piezoelectric ceramics and shape memory alloys [48-50].

The study of the $\mathrm{V}(\mathrm{I})$ characteristic at different measurement temperatures between 120 and $300 \mathrm{~K}$ (Fig. 8) indicates that it is a non-linear variation at low temperature with the presence of a negative differential resistance only in the PF/NiO nanocomposite. At high temperature, the characteristics become linear corresponding to an ohmic behavior. Generally, these types of materials are characterized by a space charge. For low applied currents, the charge carrier is strongly linked to the network and its energy does not allow it to exceed the space charge. After the application of a threshold current, the energy of the charge carrier increases and the hopping conduction becomes dominant. This observed change in the $\mathrm{V}(\mathrm{I})$ characteristic indicates the existence of two different conduction mechanisms depending on the measurement temperature. 
From the value of the resistance $\mathrm{R}$ given by the multimeter, the electrical conductivity of the material studied was calculated using the Eq. (2):

$$
\sigma=L / R S
$$

where $\mathrm{L}$ is the thickness of the pellet and $\mathrm{S}$ is the contact area with the electrode. The variation of electrical conductivity versus 1000/T (Fig. 9) exhibits the presence of two linear shapes for our materials. The curves exhibit activated temperature dependence in accordance with the Eq. (3) [51]:

$$
\sigma=A \exp \left(-\frac{E_{a}}{k_{B} T}\right)
$$

where $\mathrm{A}$ is the pre-exponential factor and $\mathrm{E}_{\mathrm{a}}$ is the activation energy. The electrical conductivity increases with measurement temperature, which proves the semiconductor behavior of our samples. According the Eq. (3), the first linear shape at low temperature with weak activation energies (56 meV for $\mathrm{PF}$ and $48 \mathrm{meV}$ for $\mathrm{PF} / \mathrm{NiO}$ ) indicating the dominance of the hopping conduction mechanism between localized states at this range measurement temperature where the $\mathrm{V}(\mathrm{I})$ characteristic is non-linear [52]. The second at high temperature with important activation energies (100 meV for $\mathrm{PF}$ and $93 \mathrm{meV}$ for $\mathrm{PF} / \mathrm{NiO})$ corresponding to ohmic conduction. In fact, in disordered materials, when the activation energy is in the order of $0.1 \mathrm{eV}$, conduction occurs through the diffusion of electrons or holes in the matrix. These results of electrical conductivity are in good agreement with the obtained V(I) characteristics.

The impedance measurements were carried out in the frequency range between $40 \mathrm{~Hz}$ and $100 \mathrm{MHz}$. The analysis of complex impedance spectra permits to have access to informations concerning the analyzed material. The experimental impedance data, obtained by impedance spectroscopy may be modeled by an equivalent circuit for each sample. Fig. 10 
shows the Nyquist plot of our samples at room measurement temperature. The variations of the opposite of imaginary part depending on real part of the impedance are characterized by the appearance of two arc-circles depressed under the real axis obeys the Cole-Cole model. Using the Z-View software, the best adjustments were obtained using an equivalent circuit formed by: $\left(\mathrm{R}_{\mathrm{p}} / \mathrm{CPE}_{\mathrm{p}}\right)$ for the $\mathrm{PF}$ matrix and another: $\mathrm{R}_{\mathrm{s}}+\left(\mathrm{R}_{\mathrm{p}} / \mathrm{CPE}\right)$ for the $\mathrm{PF} / \mathrm{NiO}$ nanocomposite, where $R_{s}$ is the grain resistance, $R_{p}$ is the grain boundary resistance and $C P E_{p}$ is the grain boundary constant phase element. The impedance of the CPE is written according to Eq. (4) [53]:

$$
Z_{C P E}=\frac{Q}{(j \omega)^{\beta}}
$$

where $\omega$ is the pulsation, $\mathrm{Q}$ is constant expressed in $\square . \mathrm{s}^{-\beta}$ and $\beta$ is a number related to the angle of rotation of the purely capacitive line in the complex Nyquist plane. The CPE describes an ideal capacitor with a capacitance $C$ for $\beta=1$ and an ideal resistor $\mathrm{R}$ for $\beta=0$. A $\beta$ value less than 1 indicates in general certain electric property heterogeneity within the material [54]. Table 3 shows the values of different parameters of two equivalent circuits. We can see that the $\beta$ values are close to 1 , indicating that CPEp is similar to a capacity [55]. The decrease in the resistance $R_{p}$ and the capacity $C P E_{p}$ with the incorporation of nickel oxide confirms that the electrical conductivity of the $\mathrm{PF} / \mathrm{NiO}$ nanocomposite is higher than that of the PF matrix. The low value of the resistance $\mathrm{R}_{\mathrm{s}}$ indicates that the grains of the $\mathrm{PF} / \mathrm{NiO}$ nanocomposite are based on particles of metallic nickel.

The electrochemical study of $\mathrm{PF}$ matrix and $\mathrm{PF} / \mathrm{NiO}$ nanocomposite for glucose oxidation was investigated by the cyclic voltammetry measurement in presence of $5 \mathrm{mM}$ glucose in $0.1 \mathrm{M} \mathrm{KOH}$ solution at a scan rate of $50 \mathrm{mVs}^{-1}$. Fig. 11a shows the cyclic voltammetry recorded in absence and presence of $5 \mathrm{mM}$ glucose for our materials. The 
absence of anodic or cathodic peaks for PF matrix indicates a negligible electrocatalytic activity of $\mathrm{PF}$ carbon matrix towards glucose. On the contrary, $\mathrm{PF} / \mathrm{NiO}$ nanocomposite presents two oxidation and reduction peaks around $0.4 \mathrm{~V}$ and $0.6 \mathrm{~V}$ respectively, in absence and presence of glucose, which are due to the electrochemical redox reaction of $\mathrm{Ni}^{2+} / \mathrm{Ni}^{3+}$ couple on the electrode surface [56]. Fig. 11b presents the calibration curve for $\mathrm{PF} / \mathrm{NiO}$ nanocomposite during successive additions of glucose from $20 \mu \mathrm{M}$ to $3.5 \mathrm{mM}$ in $0.1 \mathrm{M} \mathrm{KOH}$ at an applied potential of $0.6 \mathrm{~V}$. A significant increase in current was noticed with the addition of glucose to the solution, indicating a prolonged oxidation cycle. This can be due to the adsorption of glucose and the oxidized intermediate species on the active sites of electrode, which slow down the reaction possibly kinetic coupled with a gradual change in local $\mathrm{pH}$ on the electrode surface. So, we can deduce that the sensor based on the $\mathrm{PF} / \mathrm{NiO}$ nanocomposite is very promising for the detection of non-enzymatic glucose. Indeed, the good distribution of the nickel nanoparticles in the carbon matrix increased the electrocatalytic property of the $\mathrm{PF} / \mathrm{NiO}$ nanocomposite relative to the $\mathrm{PF}$ matrix, which we observed in the morphological study of these materials. The linear relationship between current response and glucose concentration in the range $0.05 \mathrm{mM}$ to $0.75 \mathrm{mM}$ indicates a sensitivity of approximately $76 \mu \mathrm{A} / \mathrm{mM} \mathrm{cm}^{-2}$ with a detection limit of less than $0.03 \mu \mathrm{M}$. This sensor based on the $\mathrm{PF} / \mathrm{NiO}$ nanocomposite shows similar or higher performance than nickel based glucose sensors reported in Table 4 [57-59].

The absorption spectra of PF matrix and $\mathrm{PF} / \mathrm{NiO}$ nanocomposite in the UV and visible range are presented in Fig. 12a. These spectra indicate that the absorption is important for low wavelengths. Afterwards, there is a decrease with the increase in wavelength and the appearance of absorption edges. The optical absorption coefficient near the fundamental absorption edge is found to be exponentially dependent on the incident photon energy and obeys the Urbach empirical formula Eq. (5) [60]: 


$$
\alpha=\alpha_{0} \exp \left(\frac{h v}{E_{0}}\right)
$$

where $\mathrm{E}_{0}$ is the Urbach energy that characterizes the disorder in the material and $\alpha_{0}$ is a preexponential factor. According to Eq. (5), the plot of $\ln (\alpha)$ as a function of the photon energy $\mathrm{h} v$ gives a linear shape (Fig. 12b), the values of $\mathrm{E}_{0}$ have been calculated and they are equal to 0.210 and $0.309 \mathrm{eV}$ for $\mathrm{PF}$ matrix and $\mathrm{PF} / \mathrm{NiO}$ nanocomposite, respectively. It is found that the Urbach energy has increased after the incorporation of $\mathrm{NiO}$ nanoparticles in the carbon matrix. In fact, the amorphous PF matrix is considered to be a homogeneous and dense material (no grains), the optical properties of which depend directly on the composition. After the incorporation of the $\mathrm{NiO}$ nanoparticles, the microstructure of the $\mathrm{PF} / \mathrm{NiO}$ nanocomposite is completely modified where there is the presence of grains and crystallized domains.

\section{Conclusion}

In this study, we have investigated the influence of the $\mathrm{NiO}$ nanoparticles on structural, morphological, textural electrical and optical properties of a nanoporous carbon matrix based on pyrogallol-formaldehyde elaborated by the sol-gel method. It has been shown that the incorporation of $\mathrm{NiO}$ crystallized the $\mathrm{PF} / \mathrm{NiO}$ nanocomposite with the appearance of metallic nickel nanoparticles. The adsorption capacity greenhouse gas shows that the PF matrix has the highest adsorption at low pressures and the $\mathrm{PF} / \mathrm{NiO}$ nanocomposite tends to adsorb gases better at high pressure. Indeed, the PF matrix is microporous and the $\mathrm{PF} / \mathrm{NiO}$ nanocomposite is mesoporous according to the nitrogen adsorption-desorption isotherms. The $\mathrm{V}(\mathrm{I})$ characteristics and the electrical conductivity explained the dominance of two conduction mechanisms in our samples. The electrochemical performance of the sensor based of PF/NiO nanocomposite for the determination of glucose in alkaline medium has been investigated, demonstrating that both the nickel nanoparticles and porous surface of carbon matrix offer 
particular advantages of this nanocomposite to use it in the field of detection of nonenzymatic glucose. 


\section{References}

[1] D. Jayne, Y. Zhang, S. Haji, C. Erkey, Int. J. Hydrogen Energy 30 (2005) 1287.

[2] K.Y. Kang, B.I. Lee, J.S. Lee, Carbon 47 (2009) 1171.

[3] K.P. Wang, H. Teng, Carbon 44 (2006) 3218.

[4] F.J. Maldonado-Hodar, C. Moreno-castilla, A.F. Perez-Dadenas, Microporous Mesoporous Mater 69 (2004) 119.

[5] L. El Mir, S. Kraiem, M. Bengagi, E. Elaloui, A. Ouderni, S. Alaya, Physica B 395 (2007) 104.

[6] W. Djeridi, A. Ouederni, A.D. Wiersum, P.L. Llewellyn, L. El Mir, Mater. Lett. 99 (2013) 184.

[7] M. Ishibashi, H. Ota, N. Akutsu, S. Umeda, M. Tajika, J. Izumi, et al., Energy Convers Manage 37 (1996) 929.

[8] F.A. Awadallah, S.A. Al-Muhtaseb, Adsorption 19 (2013) 967.

[9] B.K. Na, H. Lee, K.K. Koo, H.K. Song, Ind. Eng. Chem. Res. 41 (2002) 5498.

[10] P. Kowalczyk, L. Solarz, D.D. Do, A. Samborski, J.M.D. Macelroy, Langmuir 22 (2006) 9035.

[11] C.M. Yang, H. Noguchi, K. Murata, M. Yudasaka, A. Hashimoto, S. Iijima, Adv. Mater. 17 (2005) 866.

[12] U. Mueller, M. Schubert, F. Teich, H. Puetter, A.K. Schierle, J. Pastre, J. Mater. Chem. 16 (2006) 626.

[13] B. Panella, M.Hirscher, H. Putter, U. Muller, Adv. Funct. Mater. 16 (2006) 520.

[14] N.B. McKeown, P.M. Budd, Chem. Soc. Rev. 35 (2006) 675. 
[15] A. Thomas, P. Kuhn, J. Weber, M.M. Titirici, M. Antonietti, Macromol Rapid Commun. 30 (2009) 221.

[16] N. Ben Mansour, L. El Mir, Journal of Materials Science: Materials in Electronics 27 (2016) 11682.

[17] N. Ben Mansour, L. El Mir, Journal of Materials Science: Materials in Electronics 28 (2017) 11284.

[18] N. Ben Mansour, L. El Mir, Journal of Solid State Sciences 85 (2018) 38.

[19] A. Okada, A. Usuki, Mater. Sci. Eng. 3 (1995) 109.

[20] E.P. Giannelis, Adv. Mater. 8 (1996) 29.

[21] W.J.E. Beek, M.M. Wienk, M. Kemerink, X. Yang, R.A.J. Janssen, J. Phys. Chem. B 109 (2005) 9505.

[22] S.F. Wang, F. Xie, R.F. Hu, Sens. Actuators B 123 (2007) 495.

[23] N.A. Filinyuk, Proceedings of a USSR Scientific and Technical Conference on Devices with Negative Resistance and Integrated Converters on Their Basis, Baku, Russian (1991) 11.

[24] M. Zielinski, R. Wojcieszak, S. Monteverdi, M. Mercy, M.M. Bettahar, Int. J. Hydrogen Energy 32 (2007) 1024.

[25] G. Malandrino, S.T. Finocchiaro, R.T. Nigro, Chem. Mater. 16 (2004) 5559.

[26] N. Chopra, V.G. Gavalas, L.G. Bachas, B.J. Hinds, L.G. Bachas, Anal. Lett. 40 (2007) 2067.

[27] K. Kerman, M. Saito, S. Yamamura, Y. Takamura, E. Tamiya, Trends Anal. Chem. 27 (2008) 585.

[28] R.C. Jin, Y.W. Cao, C.A. Mirkin, K.L. Kelley, G.C. Schatz, J.G. Zheng, Science 294 
(2001) 1901.

[29] M. Hjiri, R. Dahari, N. Ben Mansour, L. El Mir, M. Bonyani, A. Mirzaei, S.G. Leonardi, G. Neri, Materials Letters 160 (2015) 452.

[30] S. Marini, N. Ben Mansour, M. Hjiri, R. Dhahri, L. El Mir, C. Espro, A. Bonavita, S. Galvagno, G. Neri, S.G. Leonardi, Electroanalysis 30 (2018) 1.

[31] D.M. Vriezema, M.C. Aragones, J.A.A.W. Elemans, J.J.L.M. Cornelissen, A.E. Rowan, R.J.M. Nolte, Chem. Rev. 105 (2005) 1445.

[32] H. Palza, Int. J. Mol. Sci. 16 (2015) 2099.

[33] K.C.C Van de Ven, B.E. De Galan, M. Van Der Graaf, A.A. Shestov, P.G. Henry, C.J.J. Tack, A. Heerschap, Diabetes 60 (2011) 1467.

[34] Y. Zhang, X. Xiao, Y. Sun, Y. Shi, H. Dai, P. Ni, J. Hu, Z. Li, Y. Song, L. Wang, Electroanalysis 25 (2013) 959.

[35] A.Safavi, N. Maleki, E. Farjami, Biosens. Bioelectron. 24 (2009) 1655.

[36] J. Luo, S. Jiang, H. Zhang, J. Jiang, X. Liu, Anal. Chim. Acta. 709 (2012) 47.

[37] Q. Guo, D. Liu, X. Zhang, L. Li, H. Hou, O. Niwa,T. You, Anal. Chem. 86 (2014) 5898.

[38] L.Qiao, J.Y. Yao, H.C.He, Electrochim. Acta 76 (2012) 512.

[39] Y. Liu, H. Teng, H.Q. Hou, T.Y. You, Biosens. Bioelectron. 24(2009) 3329.

[40] G. Wang, X. He, L. Wang, A. Gu, Y. Huang, B. Fang, B. Geng, X. Zhang, Microchimica. Acta 180 (2013) 161.

[41] L. El Mir, A. Amlouk, C. Barthou, S. Alaya, Physica B: Condensed Matter 388 (2007) 412.

[42] H. Saeki, H. Tabata, T. Kawai, Solid State Commun. 120 (2001) 439. 
[43] N. Ben Mansour, I. Najeh, S. Mansouri, L. El Mir, Applied Surface Science 337 (2015) 158.

[44] B. Brunauer, P.H. Emmett, E. Teller, J. Am. Chem. Soc. 60 (1938) 309.

[45] W. Djeridi, N. Ben Mansour, A. Ouederni, P.L. Llewellyn, L. El Mir, International Journal of Hydrogen Energy 42 (13) (2017) 8905.

[46] W. Djeridi, N. Ben Mansour, A. Ouederni, P.L. Llewellyn, L. El Mir, Solid State Sciences 93 (2019) 37.

[47] M. Almasi, V. Zelenak, J. Kuchar, S. Bourrelly, P.L. Llewellyn, Colloids and Surfaces A: Physicochemical and Engineering Aspects 496 (2016) 114.

[48] L.M. Cox, J.P. Killgore, Z. Li, Z. Zhang, D.C. Hurley, J. Xiao, Y. Ding, Adv. Mater. 26(2014) 899.

[49] Q. Ge, C.K. Dunn, H.J. Qi, M.L. Dunn, Smart Materials and Structure 23 (2014) 9.

[50] L. M. Cox, Z. Li, N. Sowan, D. Nair, J. Xiao, C.N. Bowman, Y. Ding, Polymer 55 (23) (2014) 5933.

[51] N.F. Mott, E.A. Davis, Electronic Processes in Non Crystalline Materials, Clarendon, Oxford (1979) 157.

[52] H. Bottger, V.V. Bryksin, Hopping Conduction in Solids, VCH Verlagsgesellschaft, Weinheim, Germany (1985).

[53] G.J. Brug, A.L.G. Van Den Eeden, M. Sluyters-Rehbach and J.H. Sluyters, J. Electroanal. Chem. 176 (1984) 275.

[54] J.H. Park, B.C. Choi, J. Cryst. Growth 276 (2005) 465.

[55]L. Nyikos, T. Pajkossy, Electrochim. Acta 30 (1985) 1533. 
[56] M. Lu, L. Zhang, F.L. Qu, H.X. Lu, X.B. Zhang, Z.S. Wu, S.Y. Huan, Q.A. Wang, G.L. Shen, Q.R. Yu, Biosens. Bioelectron. 25 (2009) 218.

[57] Y. Mu, D. Jia, Y. He, Y. Miao, H.L. Wu, Biosens. Bioelectron. 26 (2011) 2948.

[58] Y. Xing, G. Gao, G. Zhu, J. Gao, Z. Ge, H. Yang, J. Electrochem. Soc. 5 (2014) 106.

[59] D.G. Yang, P.C. Liu, Y. Gao, H. Wu, Y. Cao, Q.Z. Xiao, H.M. Li, J. Mater. Chem. 22 (2012) 7224 .

[60] F. Urbach, Physical Review 92 (5) (1953) 1324. 
Figures

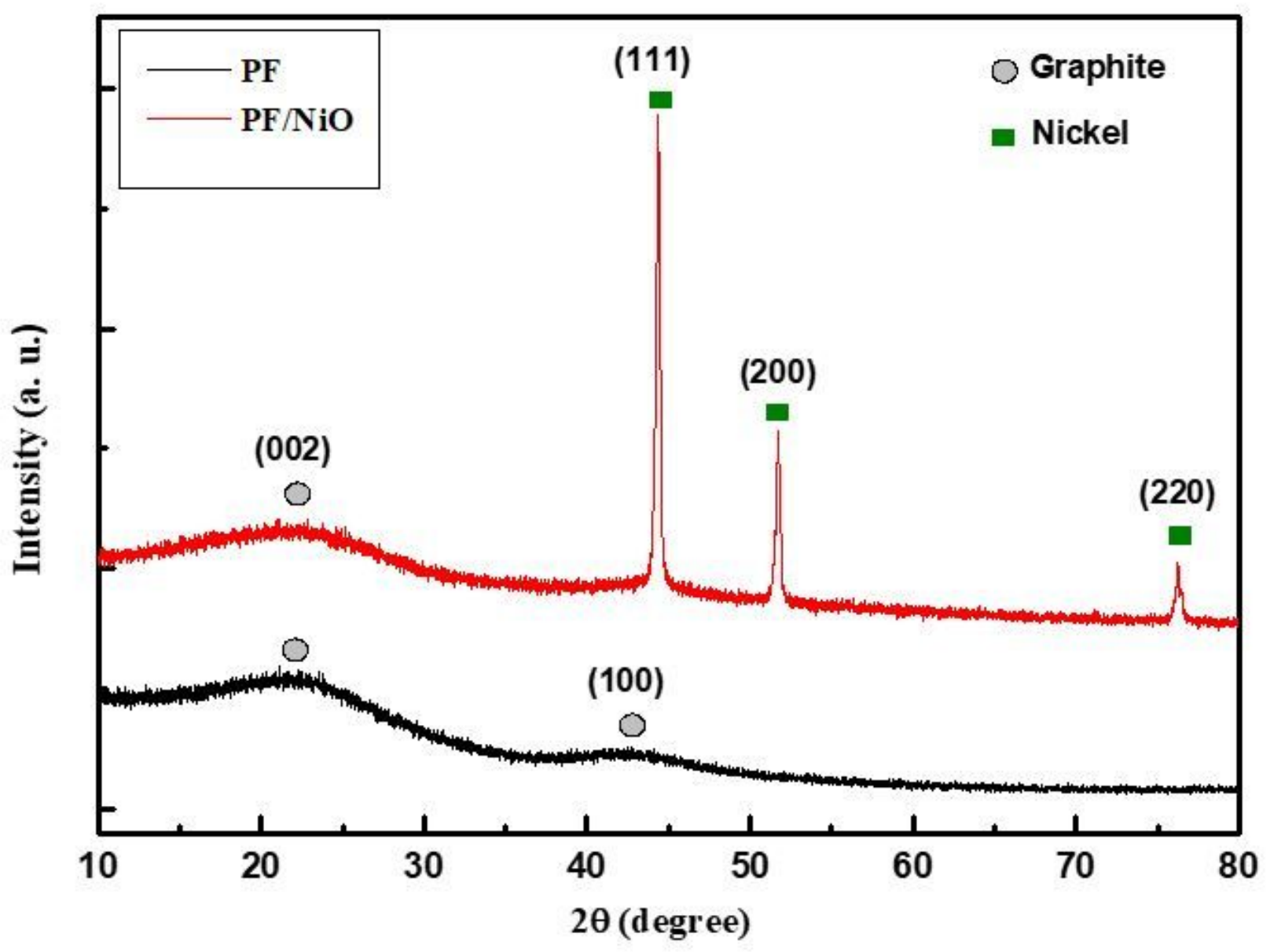

Figure 1

XRD patterns of PF matrix and PF/NiO nanocomposite. 

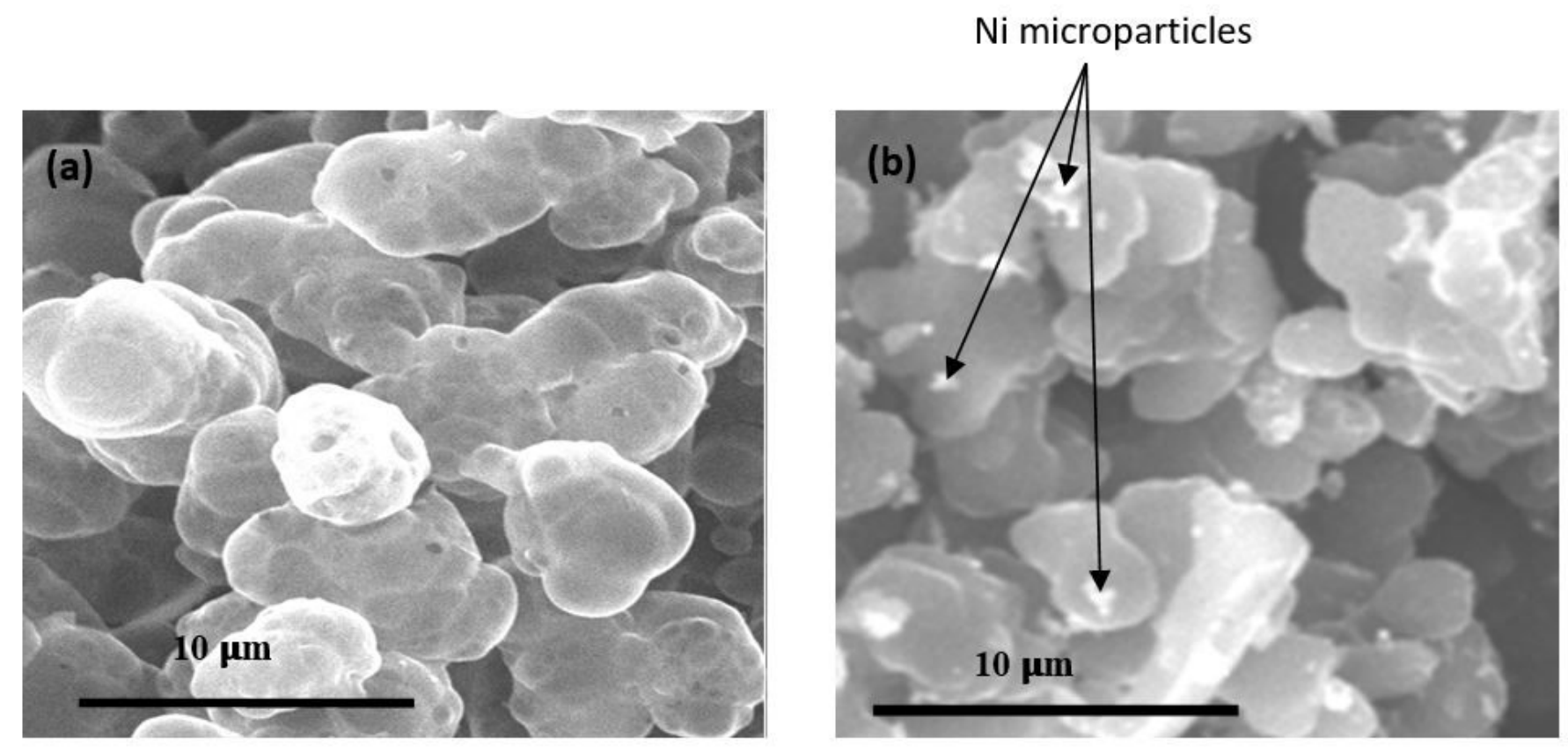

Figure 2

SEM images of (a): PF matrix and (b): PF/NiO nanocomposite.
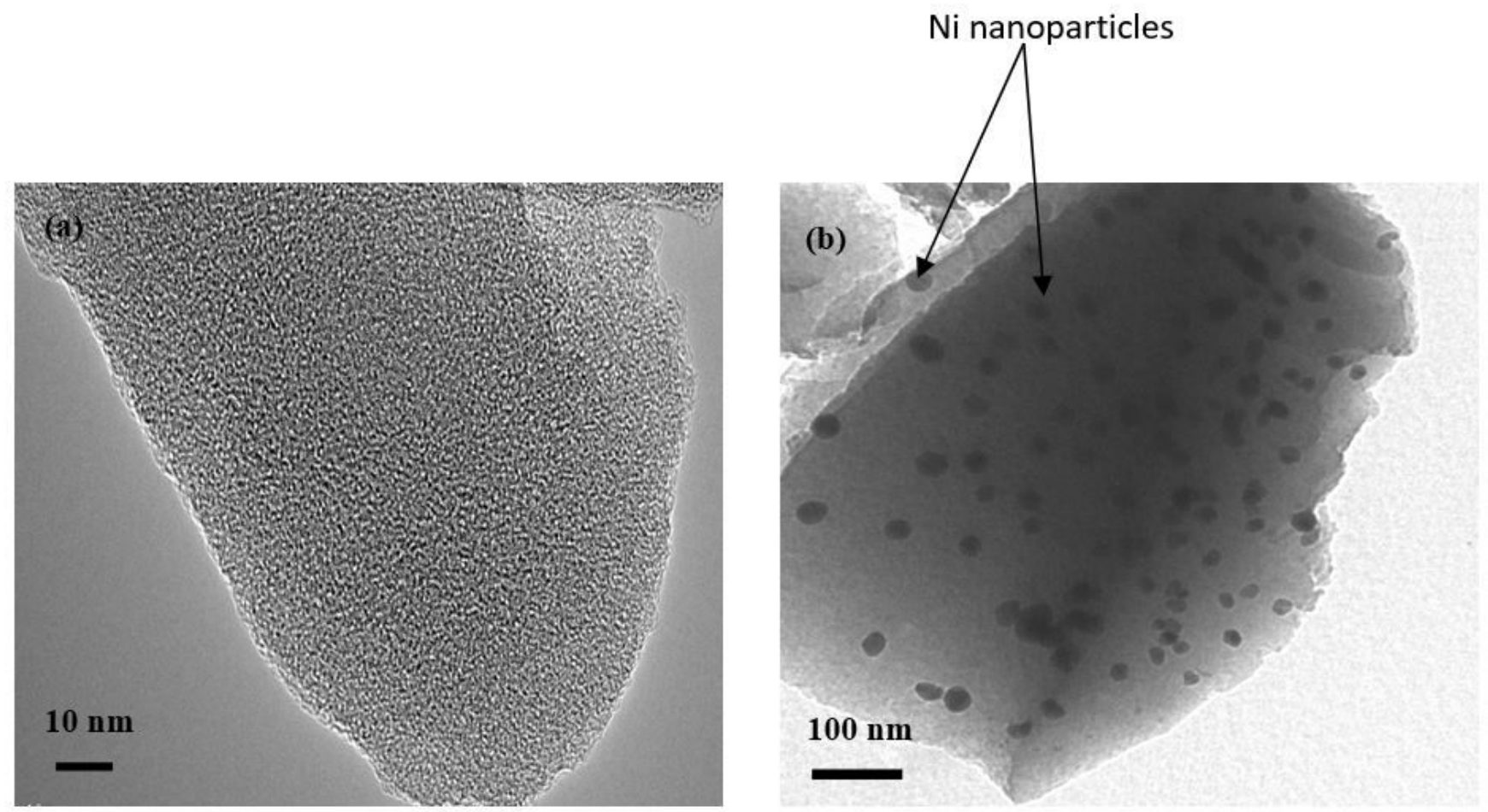

Figure 3 
TEM images of (a): PF matrix and (b): PF/NiO nanocomposite.
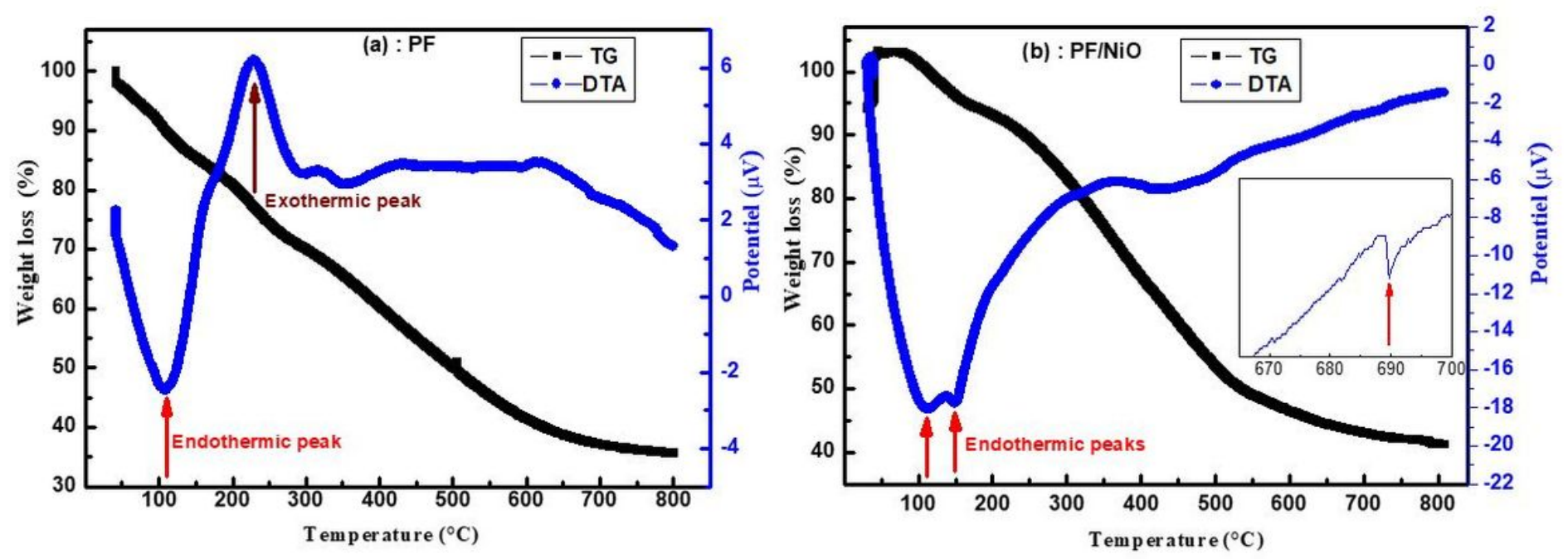

Figure 4

TG and DTA curves of (a): PF matrix and (b): PF/NiO nanocomposite.

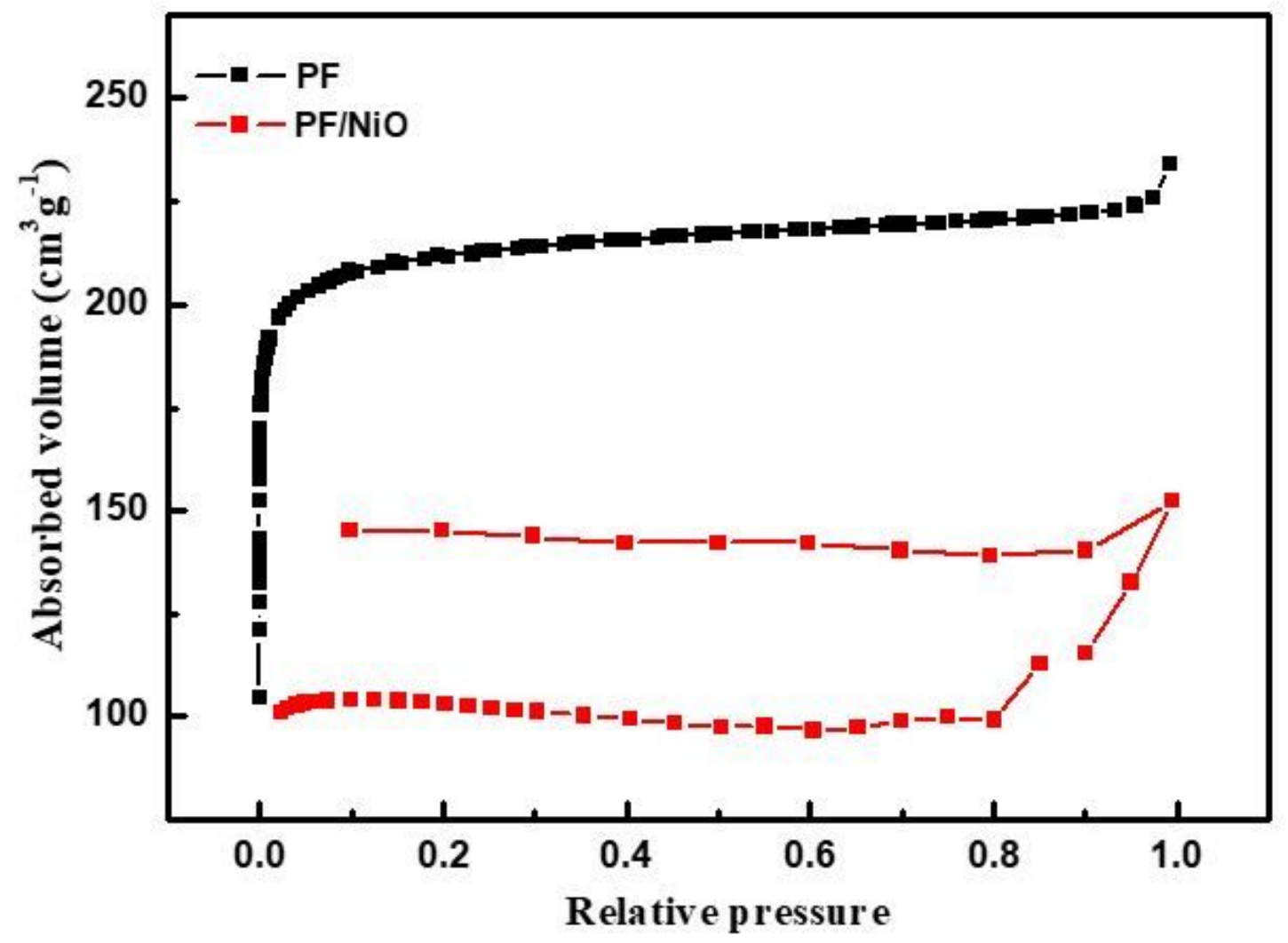

Figure 5 

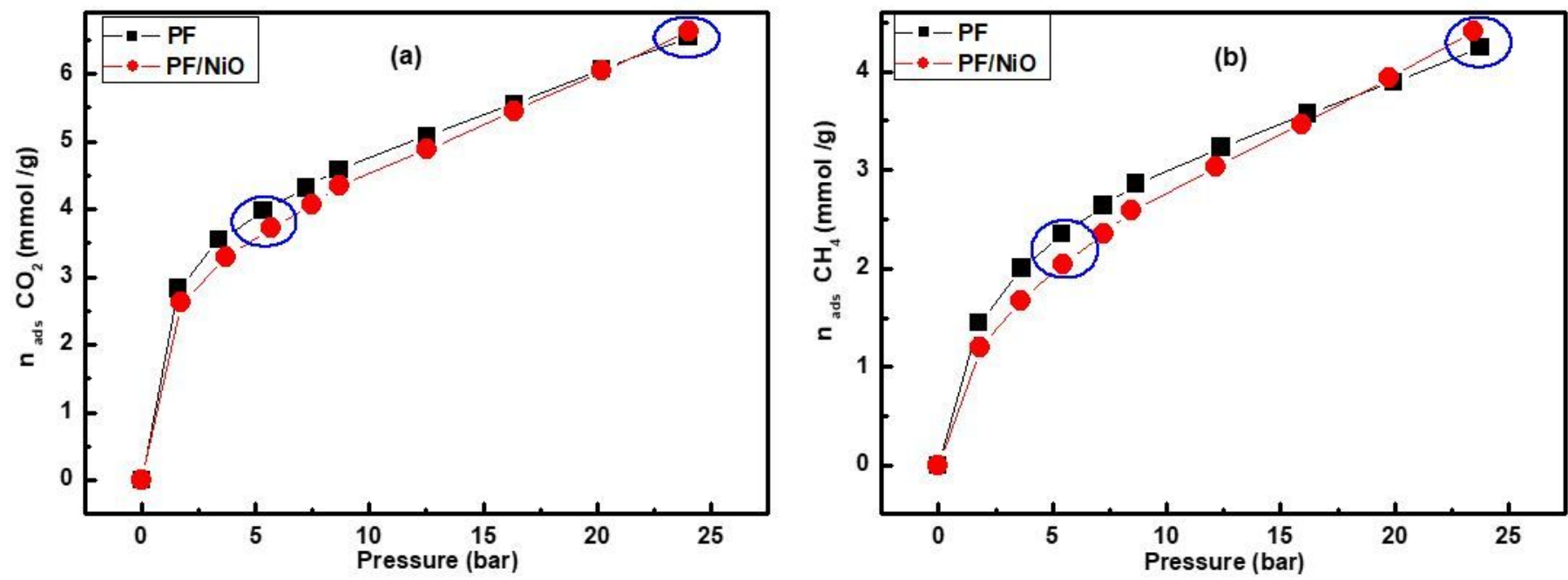

Figure 6

Carbon dioxide and (b): Methane adsorption isotherms at room temperature of $\mathrm{PF}$ matrix and $\mathrm{PF} / \mathrm{NiO}$ nanocomposite.
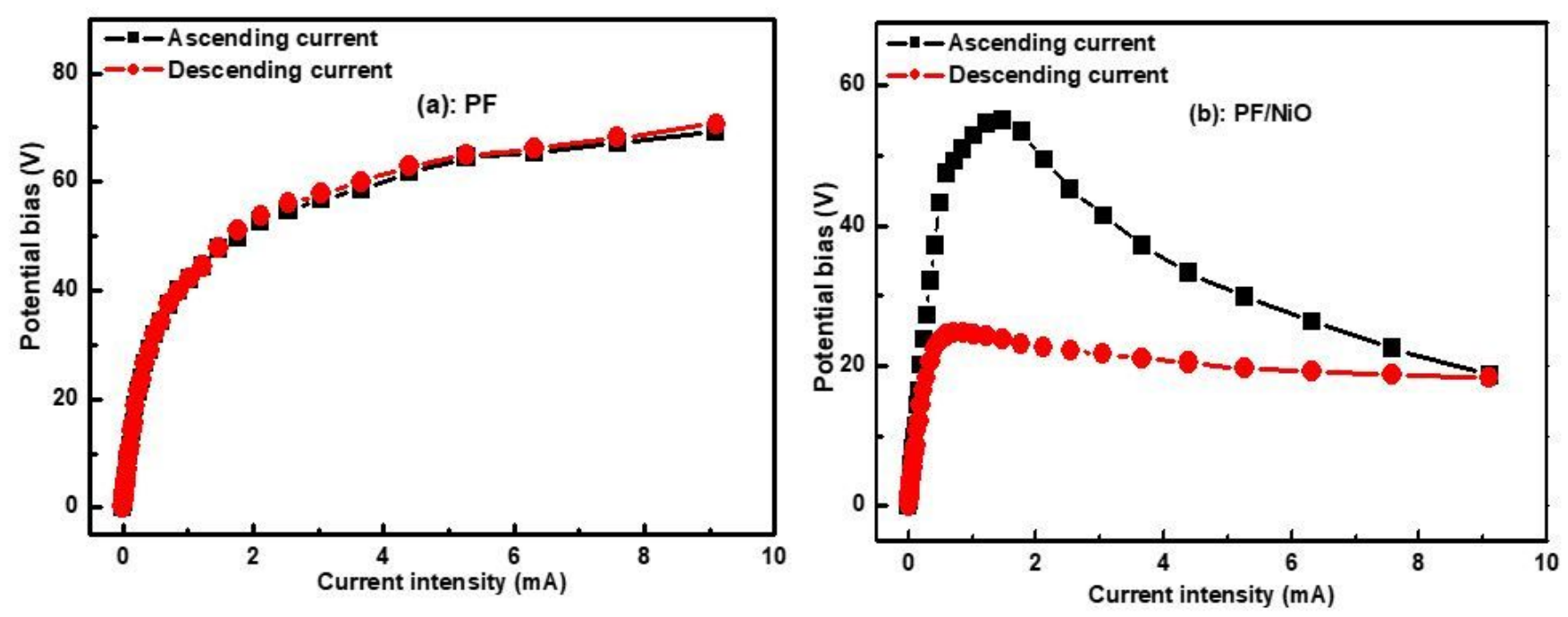

Figure 7

Voltage-current characteristics of (a): PF matrix and (b): PF/NiO nanocomposite at $120 \mathrm{~K}$. 

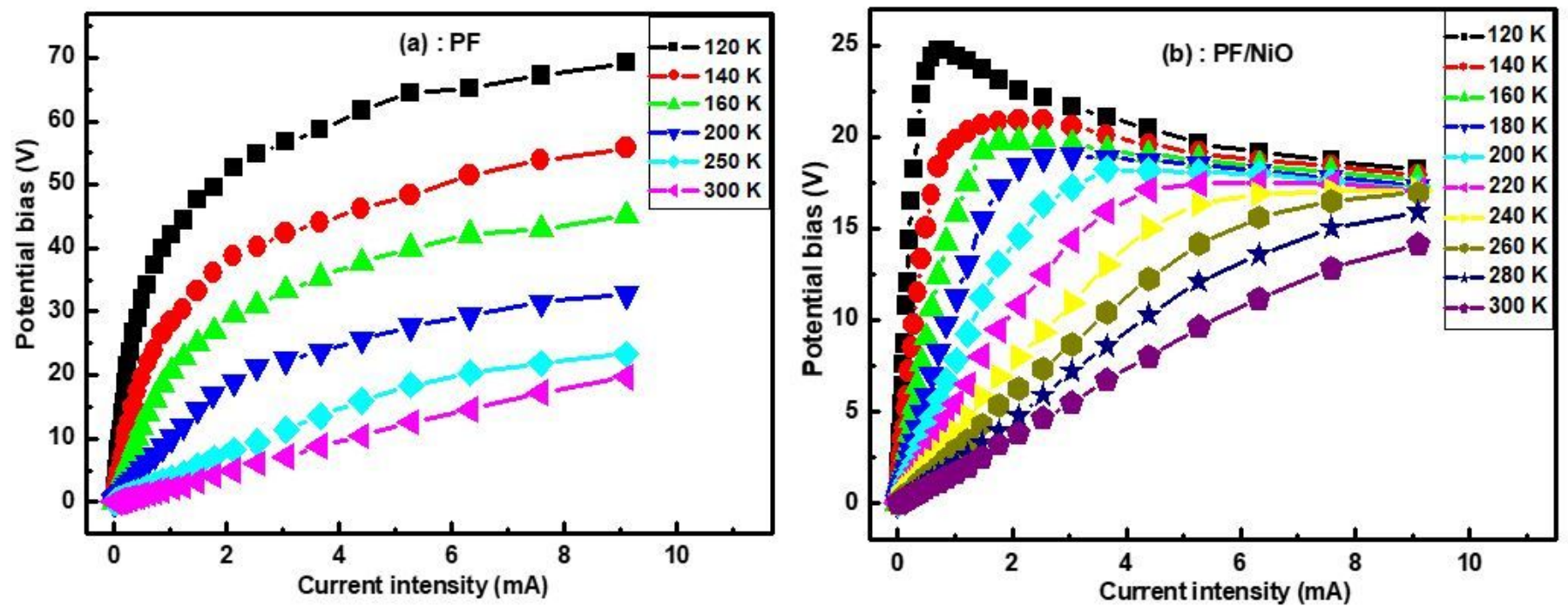

Figure 8

Voltage-current characteristics of (a): PF matrix and (b): PF/NiO nanocomposite at different measurement temperatures.

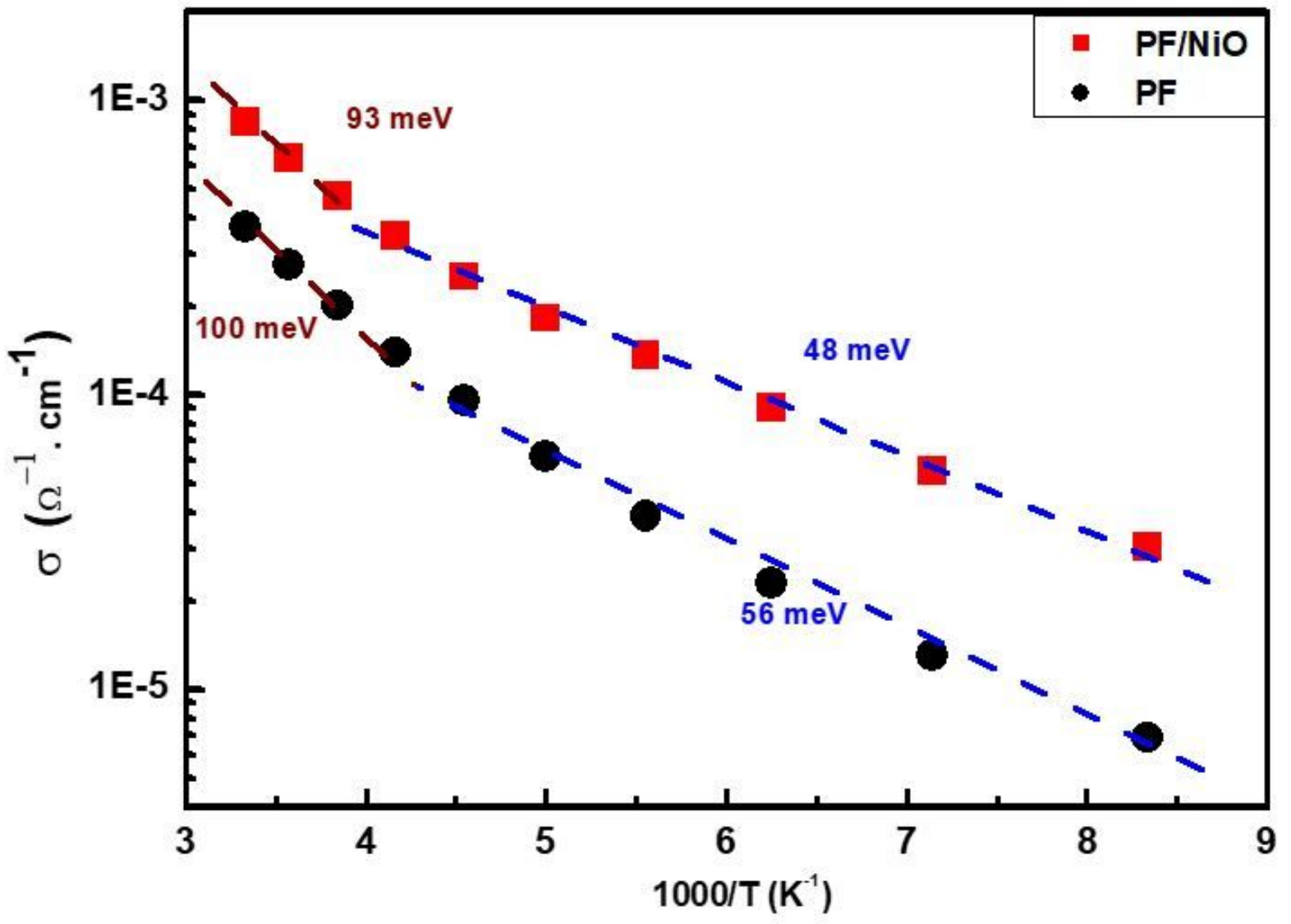


Figure 9

Variation of electrical conductivity versus $1000 / \mathrm{T}$ for PF matrix and PF/NiO nanocomposite.

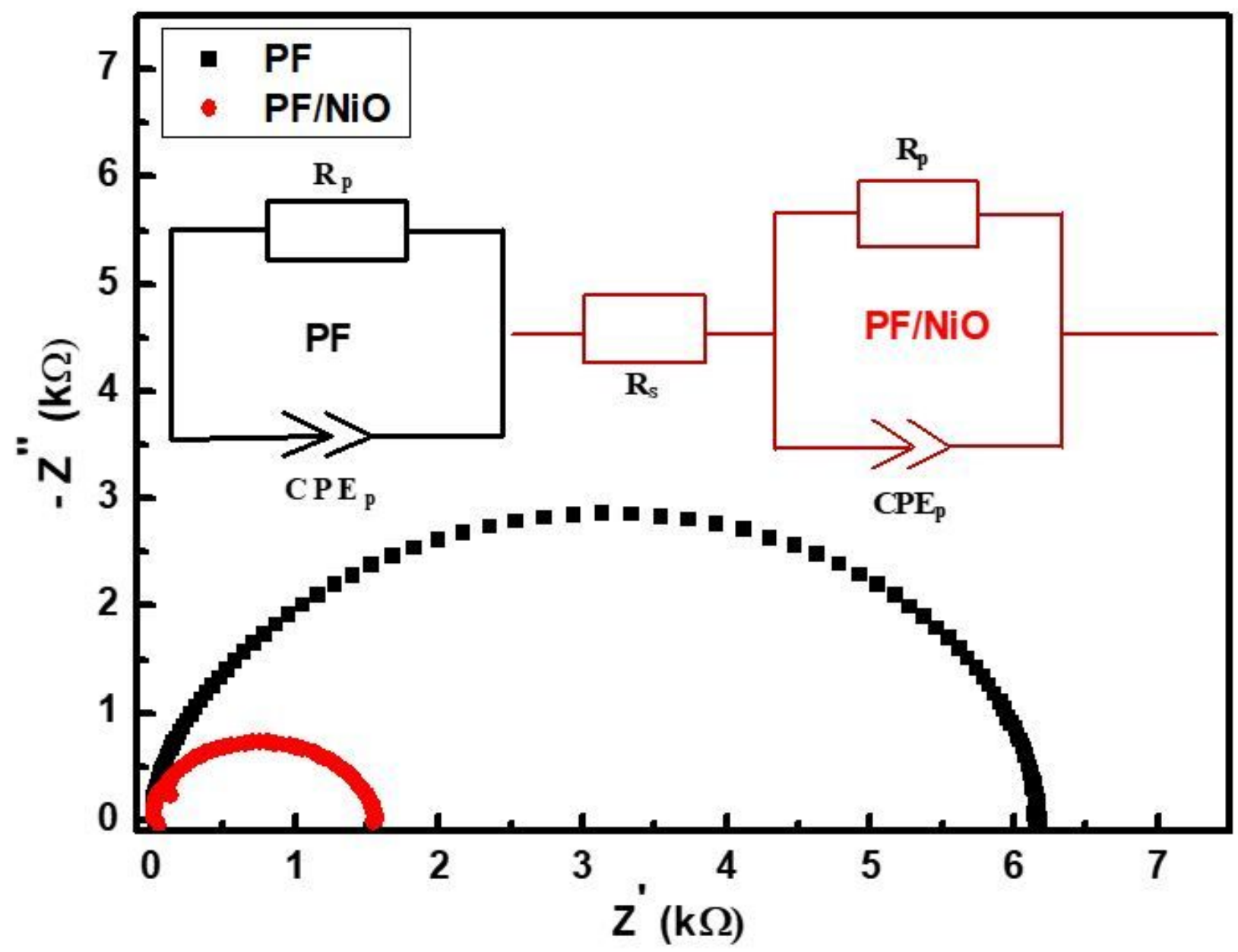

Figure 10

Nyquist plots and equivalent circuits for the PF matrix and PF/NiO nanocomposite at room temperature. 

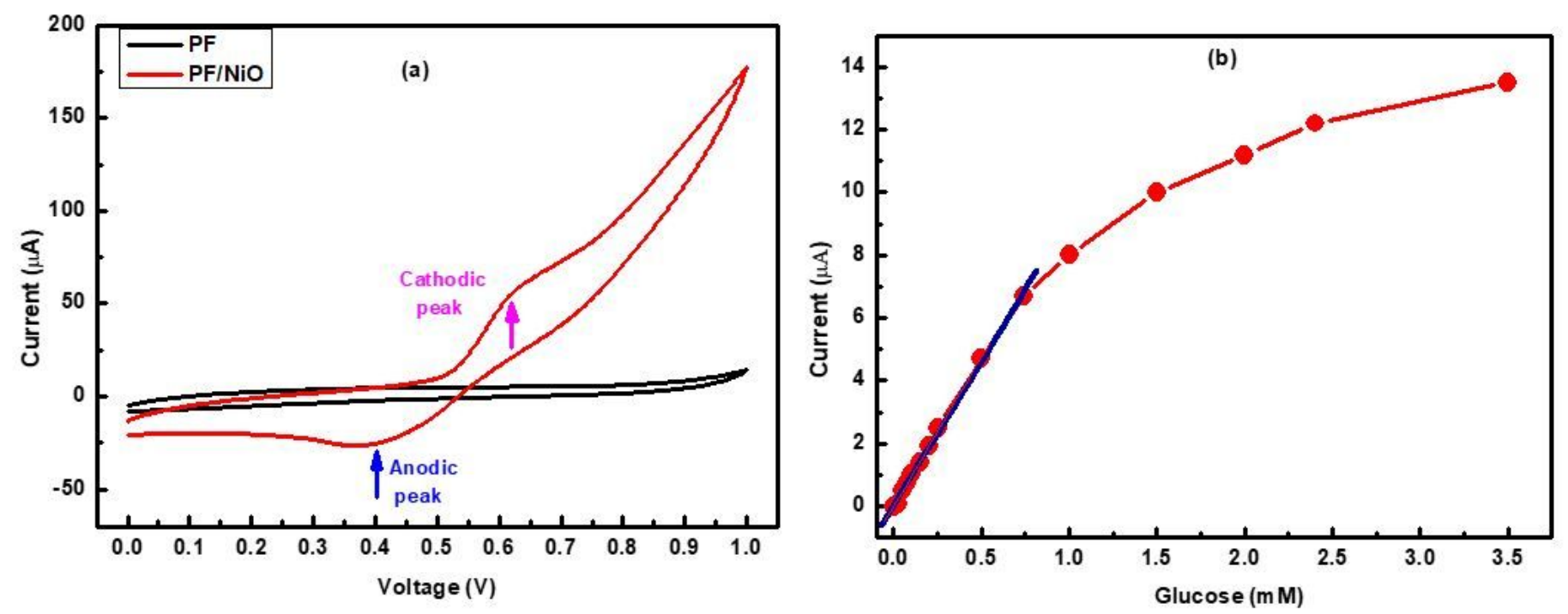

Figure 11

(a): Comparison of current-voltage curves of PF matrix and PF/NiO nanocomposite in presence of $5 \mathrm{mM}$ glucose in $0.1 \mathrm{M} \mathrm{KOH}$ at $50 \mathrm{mVs}-1$ and (b): Calibration curves of PF/NiO nanocomposite for different glucose concentrations.
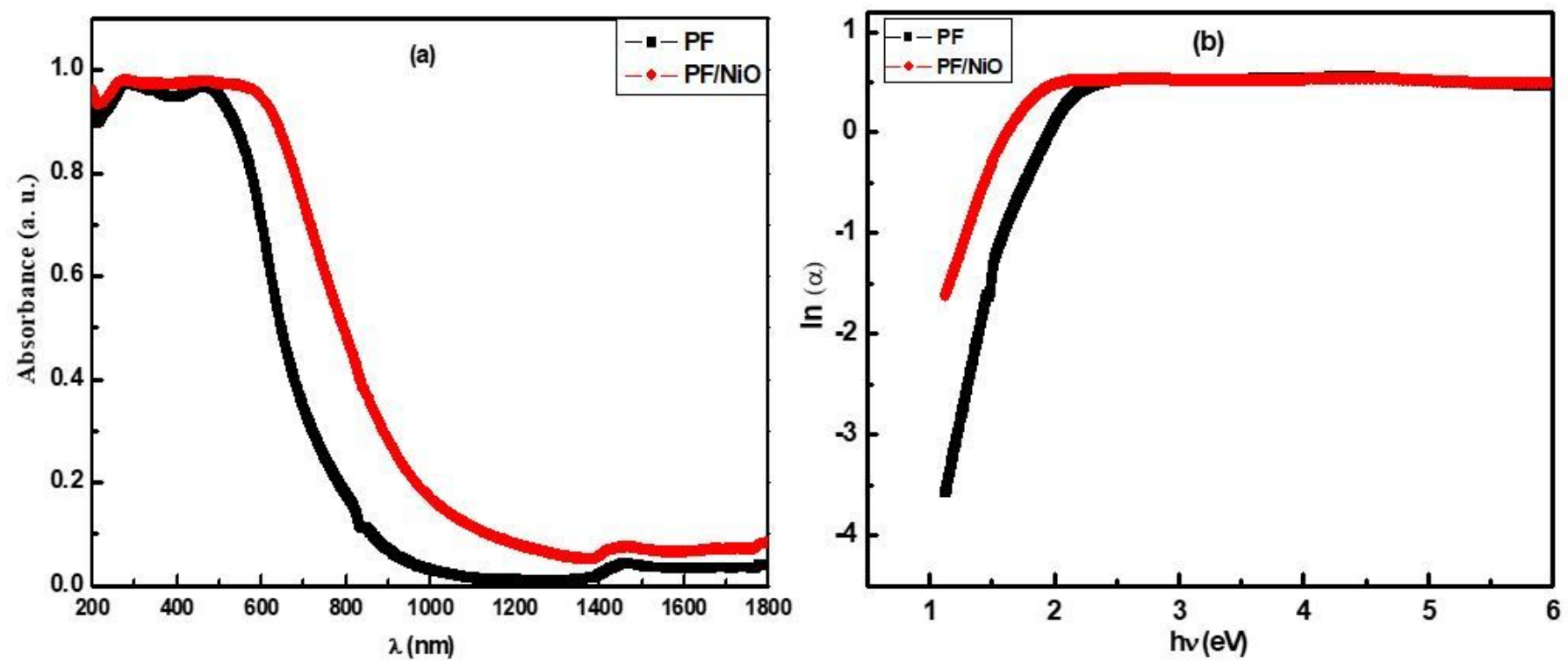

Figure 12

(a): UV-Vis-IR absorption spectrum and (b): Variation of logarithmic of absorption coefficient with the incident photon energy for PF matrix and PF/NiO nanocomposite. 